\title{
LAS MIGAS DE MIRTA ROSENBERG. RASTROS LESBIANOS EN SU POÉTICA DE LOS OCHENTA
}

\section{Ayelén Pampín García}

Instituto de Literatura Hispanoamericana, Universidad de Buenos Aires Argentina

ayelenpampin@hotmail.com

Orcid: 0000-0003-0183-4499

Fecha de recepción: I I/09/2020 | Fecha de aceptación: 20/02/2021

Resumen: La década del ochenta fue un momento bisagra para la poesía argentina. Marcada por la reaparición pública de palabras, ideas, voces que habían sido silenciadas durante la dictadura militar, tuvo lugar también -como señaló Alicia Genovese en La doble voz (1998) - la publicación de numerosos poemarios escritos y firmados por autoras mujeres. En este artículo sostengo que, en ese contexto, se produjo además otro fenómeno notable, que sin embargo pasó inadvertido durante décadas para la crítica de poesía: en los ochenta aparecieron con mayor frecuencia y de manera más explícita huellas, rastros de sensibilidades, cuerpos, afectividades y deseos lesbianos que comenzaron a modular una voz plural, heterogénea, múltiple. Propongo leer la obra poética de Mirta Rosenberg publicada en esa década -los poemarios Pasajes (1984) y Madam (1988)-, con el objetivo de señalar allí algunas inflexiones lesbianas que, plegadas sutilmente en la escritura, recorren los versos y estructuran una de las voces más influyentes e irreverentes de la poesía argentina de los últimos años.

Palabras clave: Poesía argentina; Mirta Rosenberg; Estudios literarios LGBT y Queer; Afectividad lesbiana.

\section{Mirta Rosenberg's Crumbs. Lesbian Traces in her Poetics of the Eighties}

Abstract: The 1980s was a turning point for Argentine poetry. Marked by the public reappearance of words, ideas, and voices that had been silenced during the military dictatorship, there was also -as Alicia Genovese pointed out in La doble voz (1998)- the publication of numerous collections of poems written and signed by women authors. In this article I maintain that another remarkable phenomenon occurred within the same time frame and context, though for decades apparently unnoticed by poetry critics: more frequently and explicitly there appeared traces of lesbian sensibilities, bodies, affectivities and desires that began to modulate a heterogeneous yet multiple voice. I propose reading Mirta Rosenberg's work published in that decade -the poetry collections Pasajes (1984) and Madam (1988)- highlighting lesbian nuances which run sublty 
through the verses and structure one of the most influential and irreverent voices of Argentine poetry in recent years.

Keywords: Argentine poetry; Mirta Rosenberg; LGBT and Queer Literary Studies; Lesbian affectivity.

\section{As migalhas de Mirta Rosenberg. Traços lésbicos na sua poética dos anos oitenta}

Resumo: Os anos oitenta foram um ponto de viragem para a poesia argentina. Marcado pelo reaparecimento público de palavras, ideias, vozes que tinham sido silenciadas durante a ditadura militar, houve também -como Alicia Genovese salientou em La doble voz (1998)- a publicação de numerosas coleções de poemas escritos e assinados por mulheres autoras. No presente artigo defendo que, em tal contexto, houve também outro fenômeno notável, que, no entanto, passou despercebido durante décadas pelos críticos de poesia: nos anos oitenta, traços de sensibilidades, corpos, afetividades e desejos lésbicos começaram a aparecer com mais frequência e mais explicitamente, traços de sensibilidades, corpos, afetividades e desejos lésbicos que começaram a modular uma voz plural, heterogênea e múltipla. Proponho a leitura da obra poética de Mirta Rosenberg publicada nos 80 -as coleções de poesia Pasajes (1984) e Madam (1988)- com o objetivo de apontar algumas inflexões lésbicas que, escritas subtilmente nas entrelinhas, percorrem os versos e estruturam uma das vozes mais influentes e irreverentes da poesia argentina nos últimos anos.

Palavras-chave: Poesia argentina; Mirta Rosenberg; Estudos Literários LGBT e Queer; Afetividade lésbica

$E^{\prime}$ 1 término "pasajes", palabra con la que Mirta Rosenberg decide inaugurar su obra poética publicada, tiene varias acepciones. Dos de ellas orientan fundamentalmente este itinerario. Por un lado, la que refiere a la transformación a través de un desplazamiento (pasar de una cosa a otra, de un lugar a otro); por otro lado, la que alude a la transformación en términos de la temporalidad (lo que pasa, lo pasajero). Ambas se trenzan en un acontecimiento inherente y transversal a la poesía de Rosenberg: el movimiento. Su escritura nos desafía a no permanecer, a desplazarnos con ella, a "correr /la silla al sol para rehacer /el ayer" (Rosenberg El árbol de palabras, 29). Y ese gesto intentaré emular en este trabajo: volver a leer su obra publicada hace poco más de treinta ańos desde otra perspectiva, a partir de algunas de las preguntas que atraviesan la época en que este artículo se escribe y que encuentran ecos en los versos de Pasajes (1984) y Madam (1988) ${ }^{1}$. Concretamente me propongo rastrear aspectos poco trabajados de la insistente aparición de la sexualidad que, casi siempre de manera implícita, resuenan en sus poemas.

1 Todas las citas correspondientes a la obra de Rosenberg serán tomadas de la compilación de su obra reunida titulada El árbol de palabras, publicada en 2018 por la editorial Bajo la luna y consignada en la bibliografía. De aquí en más utilizaré las abreviaturas $P J S$ y $M D M$ respectivamente para indicar a qué poemario refiere cada cita. 
Alicia Genovese señaló en La doble voz (1998) que la poesía de la década del ochenta estuvo signada por un notable incremento en la publicación y la circulación de textos escritos por mujeres. Aquí sostengo que, en ese contexto, se produjo otro fenómeno: en los textos aparecieron con mayor frecuencia rastros de imaginarios, de afectividades y de deseos lesbianos que comenzaron a articularse a través de voces poéticas insoslayables como las de Diana Bellessi, Susana Thénon, Susana Villalba y quien aquí nos convoca, Mirta Rosenberg ${ }^{2}$. Sin embargo, este acontecimiento pasó casi desapercibido para la crítica de poesía. De los poemarios publicados en Argentina durante dicha década, sólo en la escritura de Bellessi fue leído el imaginario lesbiano, únicamente allí donde el deseo estuvo explicitado en, y autorizado por, el texto: en Eroica (1988), primer poemario en el que aparece sin máscaras, sin eufemismos, ineludible, el cuerpo, el erotismo, la pasión y el amor lesbianos. Así y todo, como señaló Hilda Rais, muchas lecturas críticas mencionaron el deseo lésbico que estructura el libro apenas como "nota al pie"3. En el estudio preliminar de la obra reunida de Bellessi, Jorge Monteleone afirma que este erotismo aparece en la poesía para explorar la "constitución de subjetividad femenina de un modo absoluto, radical y necesario" (Bellessi, 14). Pero al circunscribir lo lesbiano y subsumirlo a la constitución de una subjetividad femenina, se obtura la posibilidad de leer la potencia disruptiva de las imaginaciones lesbianas para interrumpir la supuesta relación de pertenencia y correspondencia entre "lo femenino", "las mujeres" y "lo lesbiano"4. Esto último, a mi juicio, es precisamente lo que aparece en la poética de Rosenberg.

Desde mi perspectiva, la reflexión en torno a las afectividades, los cuerpos, los deseos y los imaginarios lesbianos no concierne meramente a las formas

2 Si bien sostengo que la aparición de voces sexo-disidentes -específicamente lesbianas- tuvo lugar en la década del ochenta en el campo de la poesía, en La condesa sangrienta (1966) Alejandra Pizarnik ya pervertía los códigos estéticos, morales y sexuales de la época, desplegando en su máxima expresión la irreverencia que la caracterizaba, y constituyéndose en puntapié y precursora clave de las inscripciones lesbianas que acontecieron en décadas posteriores. Para un estudio acerca de la sexualidad en La condesa sangrienta remito al artículo "De Safo a Baffo. La diversión de lo sexual en Alejandra Pizarnik" de Sylvia Molloy, referenciado en la bibliografía. Por otra parte, cabe mencionar dos libros que en el campo de la narrativa argentina, como sostiene Arnés, fueron fundacionales de las voces lesbianas: Monte de Venus, de Reina Roffé (1976) y En breve cárcel, de Sylvia Molloy (1981).

3 En "Lesbianismo. Apuntes para una discusión feminista" (1984), Rais denuncia que ciertos estudios o reflexiones feministas "incluyen el lesbianismo como un apéndice del tema "mujer" o como una nota al pie de página" (s/p).

4 El debate por la relación de correspondencia o no correspondencia entre "mujeres" y "lesbianas" emerge en la teoría y los estudios lésbicos con las intervenciones de dos pensadoras fundamentales para el lesbofeminismo: Adrienne Rich, quien acuñó el concepto de continuum lesbiano para referirse a una posible identificación entre todas las mujeres, y Monique Wittig quien en una conferencia en 1978 enuncia la famosa frase "las lesbianas no son mujeres", refiriéndose al hecho de que tanto gays como lesbianas escapan de la matriz heterosexual de pensamiento en la cual la categoría 'mujer' sólo tiene sentido en tanto el "otro oprimido" del varón en la relación heterosexual. Para profundizar en el pensamiento de Monique Wittig, remito a la compilación que realizó Beatriz Suarez Briones, Las lesbianas (no) somos mujeres, consignado en la bibliografía. 
de representación de una orientación específica del deseo o de una identidad sexual sino ante todo, como sostiene Virginia Cano, a la emergencia de un êthos en la poética local: "como modo de ser y de habitar la existencia, el tortismo constituye una mirada del mundo y nos proporciona una lengua, es decir, una manera de narrar(nos) y fantasear(nos), de posicionarse en el juego de lo (im) posible" (81). En esta línea, Laura Arnés afirma que a partir de la década del cincuenta cobra fuerza en la narrativa argentina la "voz lesbiana" que no sólo desequilibra las estructuras canónicas del deseo sino que también desbarata los binarismos de la cultura occidental: "una primera persona que tiene el potencial de desestabilizar los grandes relatos porque habilita la posibilidad de pensar el poder [...] no sólo en relación con la heteronormatividad sino en términos de control acústico: quién puede hablar, qué se puede decir, qué se puede escuchar" (16-17). El estudio de las afectividades lesbianas a partir del concepto de "voz lesbiana" habilita un distanciamiento respecto de los posicionamientos críticos que buscaron estabilizar la categoría "lesbiana" como instrumento de lectura (en muchos casos ligada a la sexualidad biográfica o identidad sexogenérica de lxs autorxs). En cambio, me permite situarme en un paradigma antiesencialista de la sexualidad y anti-mimético de la poesía, en el que el objetivo no consiste en delimitar los alcances de una supuesta "identidad lesbiana" y sus respectivas manifestaciones textuales, sino antes bien preguntar cómo operan estas afectividades en el campo en el que se inscriben, qué mecanismos de normalización corporal/textual develan, qué desplazamientos realizan respecto de las prescripciones somáticas establecidas por la heteronormatividad en el campo de la escritura poética5

A diferencia de Eroica, en los poemarios de Mirta Rosenberg que trabajaré, la crítica a la razón heterosexual no salta fácilmente a la vista: no busca visibilizar subjetividades ni deseos lesbianos, ni aparece de manera explícita el erotismo entre mujeres. Sin embargo, en mi recorrido por estos poemarios encontré versos en los que, con la sutileza que la caracteriza, Rosenberg configura entre líneas una lengua poética que sostiene incesantemente una relación tensa -a la vez de pertenencia y de incomodidad-con los interrogantes sexo-genéricos que atravesaron una década signada por la consolidación de los movimientos de las disidencias sexuales y el pensamiento feminista: ¿qué implica decir que un sujeto "es mujer"?, ¿es lo femenino el atributo inherente de los cuerpos asignados al género "mujer"?, ¿cómo operan los preceptos de la heteronormatividad y de la moral sexual sobre los cuerpos?, ¿cómo se conjugan las condiciones sexo-genéricas con

5 En ese sentido, si bien suscribo a la necesidad crítica, ética y política de "desheterosexualizar" los modos de leer literatura, este trabajo toma distancia de las lecturas que se proponen -a partir de la búsqueda, el develamiento y la definición de autoras, temas y/o personajes lesbianos-construir cánones alternativos a partir de la definición de, por ejemplo, "la literatura LGBT" o "la poesía lésbica". 
el gesto de la escritura, con el devenir escritora? ${ }^{6}$ Como veremos a continuación, a pesar del silencio de la crítica de poesía al respecto, en Pasajes y Madam aparecen numerosas huellas de un imaginario lesbiano que no sólo ponen en cuestión dichos interrogantes (y sus posibles respuestas), sino que por momentos los desarticula. Considero que, como las migas de Hansel y Gretel, es necesario rastrear estas huellas y seguirlas para que no desaparezcan, ya que constituyen las primeras manifestaciones de una voz que se fortalecerá en las poéticas (y en las políticas) de las décadas siguientes? ${ }^{7}$.

\section{Tiempo}

Algunos indicios que insinúan un êthos lesbiano en la poética de Rosenberg aparecen asociados a fenómenos correspondientes a la temporalidad. En Pasajes, por ejemplo, insiste la pregunta constante, casi obsesiva, por la duración. ¿Qué significa durar? ¿Qué dura (y qué no)? "No dura lo duro [...] /la duración del carbón está /en arder cuando lo encienden, /no en su eternidad" (Rosenberg PSJ 50-51). En este poema -titulado precisamente "La duración"- lo duro, lo que se pretende eterno son los valores de una cultura dominante y falocéntrica ${ }^{8}$ que a través de "las grandes obras del mundo" (50) -pinturas, esculturas, obras literarias- configuran un sistema moral en muchos casos conservador y caduco, como sugieren los siguientes versos: " $¿$ es mejor, / porque es moral, que una clavija cuadrada /insista en meterse en un orificio redondo /y no en uno cuadrado, pero inadmisible, /en el cual calzaría perfectamente?" (PSJ 51). Si bien esta pregunta le cabe a toda forma forzada u obligada de existir, conociendo la minuciosidad con la que esta poeta sopesa cada palabra y cada imagen no es un detalle menor que recurra a la exhibición de una relación heterosexualizada de los objetos. La diferencia morfológica de su materialidad (la clavija y el orificio, lo cuadrado y lo redondo), el acto de meter (reforzado por el gesto de la insistencia) y la imposibilidad moral de que esta acción se lleve a cabo de otra manera, a partir de

6 Tal vez la mayor inquietud de los textos críticos sobre la poesía escrita por mujeres en los ochenta fue la pregunta por la inscripción de la diferencia de género en la escritura y por las modalidades de transformación sociocultural de la condición-de-mujer que esta inscripción produciría. Estas reflexiones fueron posibles por la pregnancia que tuvieron en algunas regiones de Latinoamérica los feminismos, fundamentalmente franceses, que debatían fuertemente desde los años setenta alrededor del concepto écriture féminine (ya ampliamente discutido y superado por la crítica actual), del cual fueron exponentes clave las teóricas Julia Kristeva, Hélène Cixous, Luce Irigaray, entre otras. Para una lectura crítica de la noción de "escritura femenina" remito a artículo de Nelly Richard “¿Tiene sexo la escritura?”, consignado en la bibliografía.

7 Como nota Anahí Mallol, en la generación de poetas mujeres del noventa circulan con mayor liviandad, humor y desparpajo afectividades, deseos y cuerpos lesbianos. A este fenómeno lo denomina "lesbopop", y lo atribuye fundamentalmente a las obras de Marina Mariasch, Cecilia Pavón, Gabriela Bejerman, Fernanda Laguna, Romina Freschi y Karina Macció.

8 No puedo dejar de advertir aquí las connotaciones del significante "duro" al pensar la dimensión de la sexualidad y su condición falocéntrica. En este sentido, "no dura lo duro" expone el tono humorístico e irónico que caracteriza gran parte de la producción poética de Rosenberg. 
otras combinaciones morfológicas incluso cuando calzarían mejor, son imágenes que despliegan no sólo una puesta en cuestión de la moral en sí, sino ante todo de su condición heteronormativa. Rosenberg metaforiza la compulsión moral de la "heterosexualización" de los modos de existir y de relacionarse, fenómeno que está en sintonía con lo que la pensadora y poeta Adrienne Rich había denominado "heterosexualidad obligatoria" en $1980^{\circ}$. Sin embargo, el deseo desborda los moldes, y las duras prescripciones de la moral se hacen arena ante el "sentido ingobernado /de que la cosa es, moral o no, duradera /cuando es, en sí misma renovable, inacabada" (Rosenberg PSJ 52) ${ }^{10}$. Encuentro en estos versos resonancias (anacrónicas) con la concepción del "deseo lesbiano" que Teresa de Lauretis despliega en 1999: "el deseo del sujeto lesbiano no tiene límites: es un proceso repetido de desplazamiento, y recarga su deseo en un movimiento hacia objetos que pueden evocar lo que nunca estuvo allí, y que por tanto no puede ser reencontrado sino sólo encontrado [...] una vez y otra, siempre de nuevo" $(\text { Sáez, 177) })^{11}$.

En consonancia con las voces feministas de la época, Rosenberg discrepa con los saberes androcéntricos de la razón y de la ciencia, que se pretendían-como la moral heterosexual dominante- eternos y universales. En ese sentido, su poética se ocupa de "[...] ser, la loca y desdecir /lo que el monarca /ha instaurado en mí de su adorado /esqueleto de dominio, de razón" (MDM 67), y declara que "[...] medir la realidad /por la crudeza de la copia es desvelo /de científico que apena al corazón y, /por prolífico, resiente la sanción y no la llena" (MDM 76). Pero al mismo tiempo, sus versos disienten respecto de algunas premisas de corte esencialista que el feminismo dominante en esa época sostenía acerca de la relación entre las escritoras mujeres y la escritura. En ese sentido, la poesía de Rosenberg no define ni reivindica un supuesto "universo de lo femenino"; en todo caso, explicita las complejidades de la condición generizada de la enunciación poética. Rosenberg marca diferencias genérico-sexuales en su escritura, pero no teje una "escritura femenina" ajena a cualquier gesto identificado como masculino por la cultura dominante. Los quehaceres domésticos, lo cotidiano, el plano de la emocionalidad y la intimidad, la poetización de "las chucherías cadentes para dama" ( $M D M 71)$, de "las uñas manicuradas" ( $M D M$ 68), se trenzan en sus versos con atributos culturalmente asignados a lo masculino (la abstracción, la reflexión, el abordaje de interrogantes filosóficos). Al yuxtaponer recursos, elementos y temas de los imaginarios tradicionales de lo femenino y de lo masculino, su poética disuelve las fronteras entre uno y otro dejando expuesta la condición

9 Me refiero al célebre texto "Compulsory hetrosexuality and lesbian existence" (traducido como "Heterosexualidad obligatoria y existencia lesbiana"), por primera vez publicado en 1980 por la revista Signs: journal of women un culture and society, vol $5, \mathrm{n}^{\circ} 4$, University of Chicago.

10 El destacado es mío.

11 Tomo la cita del libro Teoría queer y psicoanálisis, de Javier Sáez, consignado en la bibliografía. 
ficcional de esa escisión ${ }^{12}$. De esta manera, de forma radical y temprana como pocas, Rosenberg interrumpe y desbarata la cadena de binarismos jerarquizados que heredamos de la cosmovisión moderna occidental. Y desmaterializa también otra frontera sumamente atravesada por la ficción reguladora del género: la que divide pensamiento y cuerpo. Su poética es reflexiva pero no en el sentido cartesiano; piensa con el cuerpo, a partir del cuerpo, a veces contra el cuerpo. Es una poética para la cual pensar, reflexionar, no es sinónimo de saber ni de comprender: "he mirado la acacia y la sucia /combadura del pasto en la llovizna /sin atreverme /a comprenderlas [...] sé que debo amar lo incomprensible con este amor improbable" (PJS 19). Es en todo caso un acto, una "orientación" (Ahmed), una pasión, que no puede experimentarse sino a partir de su anclaje corporal que es, a su vez, temporal.

En ese sentido, una de las llamativas figuras a partir de las cuales la condición sexo-generizada de los cuerpos aparece en Pasajes es la del contratiempo:

al azar el contratiempo

del género mujer-

hombre- (PJS 21).

La experiencia del género como un contratiempo (como un infortunio, una situación adversa, una demora) se atribuye en primer lugar al género "mujer". Sin embargo, en un movimiento característico de su poética, Rosenberg rápidamente matiza esa asociación directa y-desarmando las expectativas de cualquier feminismo de corte fuertemente separatista- agrega "hombre" en el siguiente verso. Tal vez, lo que aquí se sugiere es que el mayor contratiempo es el género como matriz de inteligibilidad, en tanto maquinaria de producción de (a) normalidad (Butler), y que las modalidades en que los cuerpos incorporan las normas de género suscribiéndose a las categorías hombre/mujer con mayor o menor grado de adecuación son diversas formas del contratiempo ${ }^{13}$. Rosenberg, sin embargo, no homologa la experiencia de una y otro en su condición temporal; inscribe la diferencia de género a través de un recurso gráfico y rítmico (el silencio del espacio en blanco) en ese desfasaje que se observa entre el segundo y el tercer verso. Pero de ninguna manera las coloca como experiencias diferentes

12 Sobre el debate que signaba la década del ochenta respecto de la "escritura femenina", Nelly Richard sostiene que la escritura no es indiferente a la diferencia genérico-sexual; afirmar algo similar sería volverse cómplice de las maniobras del discurso masculino hegemónico que se disfraza de impersonal y neutral para borrar sus exclusiones de género, entre otras. Sin embargo, para evitar la esencialización de la relación entre una subjetividad específica situada en coordenadas geo-temporales (mujeres) y la idea universal de lo femenino, la autora agrega que "no tenemos por qué pensar que la cultura de las mujeres obedece a la única clave-monosexuada-de lo femenino" (17).

13 Deleuze hace una lectura de la filosofía de Spinoza en la que propone pensar la velocidad propia de cada cuerpo como una modulación clave del mismo a la hora de considerar su relación con los otros cuerpos (y sus diversas velocidades): "modo de ser es eso: una relación de velocidad y lentitud (...) sobre el plano fijo de la sustancia absolutamente infinita" (46). 
en sí, antagónicas, opuestas. Mujer, hombre, son modos de la subjetividad que no pueden darse sino bajo la forma del contratiempo: aquello que, a la vez que nos prescribe puntualidad, nos demora; aquello a lo que nunca se llega a tiempo. Si, como la poeta afirma, "a tientas, el ritmo es todo" (PJS 15), entonces el pulso desacompasado del contratiempo, más que un infortunio, sería una forma diferente de habitar la temporalidad, un modo de ir en contra del tiempo puntual, a contrapelo de la "crononormatividad" (Freeman) ${ }^{14}$. Puede desembocar en búsquedas de diversos ritmos que disputen, siempre a tientas, el todo, el pensamiento normativo de la totalidad.

\section{Escribir contra el espejo}

Anahí Mallol ("Escritura y subjetividad") sostiene que en los ochenta se produjo un giro en la tradición literaria de las mujeres en Argentina a partir del cual "las escritoras articularán una doble operación de búsqueda y construcción de sí que apela constantemente a una recategorización de la experiencia, en tanto constitutiva de una identidad de género" (34) ${ }^{15}$. Coincido en parte con esta afirmación, pero considero que no es el caso de Rosenberg quien -como ya sugerí y seguiré profundizando en las próximas páginas- constantemente trastorna en sus versos la dicotomía estable de género, la noción misma de identidad y, por supuesto, la naturalización de la relación entre estos dos elementos.

La escritura, para Rosenberg, supone sospechar del amparo que reciben ciertos significantes cuando se vuelven incuestionables, como el término "palabra" o "mujer": "se va pasando /el pasado. /La que ha llegado /ha de entrar, abrir, cercar, /cascarse /sobre la mesa y roer/piedras custodias /de la piedra palabra, /mesa, /mujer" (PJS 30). La piedra "mujer" debe ser roída, corroída en tanto designe una identidad estable, cristalizada. Y este gesto debe ser asumido por la(s) que llega(n). Estos versos son particularmente sugerentes si se tiene en cuenta que la poeta, como muchas feministas de la época, no declinaba la categoría "mujer". Sin embargo, consciente de la temporalidad de los sentidos de las palabras, su poesía da lugar a una inquietud que por esos años apenas se gestaba y que se consolidará en el pensamiento feminista de las décadas siguientes a través, por ejemplo, de los estudios queer y la puesta en tensión de las políticas de la identidad. Escribir, hablar, nombrar, también son, en ese sentido, acciones profundamente temporales y corporales: es necesario "cascarse sobre la mesa" y, siguiendo

14 Elizabeth Freeman acuñó el concepto de crononormatividad para exponer el enlace tenaz entre la concepción dominante de la temporalidad (progresiva, lineal, teleológica) y la sexualidad. Como afirma Dahbar, siguiendo los lineamientos de Freeman, "[1]a crononormatividad [...] reconoce una cierta línea de progresión temporal en la que se es demasiado joven o demasiado grande para ciertos hitos normalizadores de la sexualidad como lo son la institución del matrimonio o los hijos" (234).

15 El resaltado es mío. 
al pie de la letra los versos de Rosenberg, roer luego también la mesa, los propios lugares sobre los que nos cascamos para enunciar.

Me interesa entonces abordar las inflexiones del yo en estos poemarios. Si bien son diversas, podrían agruparse con mayor o menor grado de adecuación en dos movimientos que, aunque a primera vista pueden parecer antagónicos o contradictorios, no lo son: por un lado, en la escritura opera una disolución, una dispersión del sujeto poético de enunciación, fundamentalmente en Pasajes; por otro lado, sobre todo en Madam, aparece un yo más compacto, de contornos aparentemente más definidos. Ambas modulaciones, aunque con estrategias diferentes, ponen en cuestión el yo heredado de la modernidad: totalizante, monolítico, idéntico a sí mismo, dueño de su voluntad.

El movimiento de disolución del yo aparece en los primeros versos publicados por la poeta, en pasajes como "he perdido la ilación /de ser yo misma" (PJS 14), "nuestra propia quietud /aquí /es delgada y grueso /el movimiento que alarga /la transición de ser a deshacer" (PJS 20), "cascada /permanece, quebrada, /facetada /destella para que oigas" (PJS 34). El agrietamiento, la transición constante hacia la disolución, la pérdida de ilación de una misma son figuras recurrentes en sus poemas y responden a un signo de época. Muchas escritoras mujeres enuncian desde un yo con el que comparten algunos de estos rasgos. Sin embargo, como mencioné, la poética de Rosenberg explicita que cada vez que dice "yo" no designa una identidad preexistente: "Mito. Yo." (PJS 39). La poeta nos alerta respecto de la naturaleza ficcional, mítica, de los pronombres personales. Sugiere que "yo", "nosotros", "nosotras" no aglutinan identidades dadas e incuestionables, sino que constituyen efectos discursivos de la construcción de cada poema ${ }^{16}$. Tal vez la irrupción lesbiana en su obra resulte tan escurridiza precisamente porque no designa la identidad sexual de un "yo" o un "nosotras", sino que se pliega en la escritura para socavar los fundamentos heteronormativos de la relación des-historizada entre subjetividad e identidad, entre cuerpo y género, entre género y el binomio femenino/masculino.

En Pasajes, la figura más clara del movimiento de disolución aparece en el apartado "Contra el espejo". El poema titulado "El arte de lo infinito" nos presenta una mujer que mientras barre imagina que es como el polvo que arrastra hacia afuera con la escoba: "semejante /a mi propia imagen, excedida /en el polvo disperso" (46). Rápidamente la escena doméstica se restituye, haciendo polvo el ensueño: ella, la mujer, vuelve en sí, y sólo barre en silencio. Sin embargo, la fantasía de la metamorfosis ya operó una transformación: "O bien, venida aquí /creo desde ya /que aquí es mi casa y yo /he vuelto" (46). Luego de imaginar la excur-

16 En ese sentido, aunque no es el propósito de este trabajo desarrollarlo, podrían considerarse las singularidades de la subjetividad en la escritura en consonancia con lo desarrollado en el apartado anterior respecto de la condición sexo-generizada de los cuerpos; es decir, en términos de ritmos, de contratiempos, de pulsos que a veces pueden acompasarse con otros y otras veces desajustan el compás de la composición. Sobre este punto encuentro sugerentes resonancias con los conceptos de "ritmo" y "sujeto de la escritura" desarrollados por Henri Meschonnic. 
sión se vuelve a la casa, como si una efectivamente se hubiera ido. "Barrer" significa devenir polvo, barrerse, disolverse en el aire hacia afuera. La única posibilidad de decir "yo" es el exceso de sí, su dispersión. Sobre este punto Mallol ("Escritura y subjetividad") afirma: "no hay yo (mucho menos un interior del yo), no hay lenguaje expresivo (sino constructivo), no hay tú. Por eso el acto de habla se vuelve mentira, o verdad en fuga por el acto mismo de la enunciación" (44). No es casual que el sujeto de enunciación en el apartado "Contra el espejo" esté más anclado en experiencias históricamente relacionadas al género "mujer" (barrer, freír, criar, cocinar). Estas tareas nunca se realizan de manera plena y en los versos adquieren múltiples aristas. Aparecen atravesadas por la incomodidad, la ajenidad, como un proceso que se hace, efectivamente, contra el espejo y no frente a él: contra los modos tradicionales de ser mujer en la cultura, contra la propia incorporación de esos mandatos socioculturales (recordemos el célebre "no puedo ser la acacia /y debería" -Rosenberg PJS 19- en un poema dedicado a sus hijos).

Pero de lo que se trata también este apartado es de ir en contra del espejo en tanto dispositivo de individuación privilegiado que refleja -y permite distinguir en los primeros momentos de la vida- los contornos del yo. Rosenberg, en cambio, afirma: "Empezar donde el yo termina /como medida -¿¿de precaución, /de defensa mejor?- desborda /a la voluntad" (PJS 50). En esta imagen -la de un sujeto que sin proponérselo, a través de un gesto ajeno a su voluntad, empieza donde el yo termina- resuena la concepción de subjetividad de Judith Butler (1990), en la que el sujeto no ostenta una identidad estable, sino que es efecto (siempre cambiante) de procesos citacionales. La cita, de hecho, es un fenómeno que atraviesa todo el poemario de Rosenberg, plagado de pasajes e intertextualidades que en algunos casos quedan implícitas, y en otros casos se encuentran consignadas en el apartado final, "Itinerario", en el que la poeta explicita las fuentes en las que inspiró (o directamente copió) muchos de los versos.

En Madam el yo poético es más compacto que en Pasajes, sin embargo, tampoco constituye una unidad identitaria. En este libro Rosenberg trastorna de manera radical uno de los pilares de la constitución de subjetividad occidental, la cristalización sexo-genérica de la identidad. Madam es, por momentos, una personificación de la feminidad tradicional: "verdadera dama [...] corazón de muselina/ fina, exclusiva, bella, y ella /recibe en casa" (61); pero al dar vuelta -literalmente- la página, encontramos una madam que, gracias a la alquimia de la palindromía, transiciona: "Madam, I’m Adam -más perfecta en otro idioma" (62). En estos versos se interrumpe una de las premisas más arraigadas en la relación entre cuerpo-género-lengua: la concordancia del género gramatical con el de aquello que se designa. Adam es perfecta, y es perfecta en ese otro idioma que, a diferencia del español, no posee tantas marcas de género. Pero "otro idioma" puede referirse también al español cuando, trampeado en una de sus premisas fundamentales, se vuelve extraño para sí mismo. La madam se declara además demente (otro golpe al centro de la subjetividad normativa occidental): "Mad i am" (62). El poema desemboca, finalmente, en lo que podría leerse como un 
suspiro agotado de desplazamientos irreverentes, o bien como una última insolencia: un gemido lesbiano ("Madam, jay!" -62-) ${ }^{17}$.

A través del juego de (y con las) palabras, Rosenberg se burla de los pilares que constituirían el yo: lo masculino y lo femenino como aspectos dicotómicos, excluyentes y estables de género; el género como aspecto fundamental de la identidad de los sujetos; y la identidad como efecto de individualización exitosa del proceso de subjetivación, a partir de la cual quedarían definidos y quietos los contornos del yo. Plegando sutilmente entre sus versos desobediencias respecto de los imaginarios sexuales dominantes disponibles en la década del ochenta, Rosenberg delineó una poética del movimiento en la que sólo dura lo que no permanece. Ella (madam, Adam, mad, solterona) "[...] en los secretos cajones / del dressoir no guarda nada final, definitivo" (MDM 61).

\section{Secretos}

En Pasajes y en Madam se arman constelaciones de sentidos a partir del uso de todos los recursos del lenguaje, tanto desde el aspecto semántico como desde el sintáctico y, tal vez ante todo, desde el aspecto musical de la lengua. Rosenberg es una de las poetas argentinas que con más destreza y oído captó ritmos, melodías. A partir del corte de verso, la aliteración, el juego ni ingenuo ni absolutamente gobernado con los sonidos, nos legó una poesía musical. Sus versos asumen de manera constante un compromiso con la multiplicidad de dimensiones y aristas de las palabras: "Donde era en blanco /hay palabras /que siguen planas. Necesito mi vergüenza /para combarlas, trazarlas plásticas, /húmedas, auríferas, lunares, /desquiciadas, excéntricas" (PJS 32-33) ${ }^{18}$. El gesto de su escritura es el de dar formas, texturas, matices a la lengua para perturbar la premisa -todavía arraigada en el sentido común- de que la función principal del lenguaje sería la de significar de manera transparente lo que se pretende decir. Escribir, en cambio, es tejer "un velo, vellos/trenzados, pelos que /me develen la entrada" (PJS 33). La poesía de Rosenberg despliega no sólo el carácter temporal de la escritura sino también sus posibles cartografías textuales y corporales. Cartografías veladas, opacas, que exigen una lectura entre líneas. Resulta sumamente

17 Respecto del carácter lesbiano de este último verso, Paula Jiménez España realizó una lectura similar en "Sin repetir y sin soplar", artículo publicado en Página12 con motivo de la muerte de la poeta. La nota está disponible online en este enlace: https://www.pagina12.com.ar/204142sin-repetir-y-sin-soplar

18 En estos versos aparece fuertemente una línea de lectura que no podré desarrollar por razones de espacio pero que no quiero dejar de mencionar: el quehacer poético de Rosenberg con la palabra es un trabajo afectivo y afectado en el que intervienen diversas formas de "afectos negativos" (Heather Love) como la vergüenza, el miedo, la incertidumbre, el dolor. Estos afectos, que históricamente cumplieron una función clave en las economías afectivas vinculadas a la sexualidad (el adoctrinamiento, el silenciamiento, la humillación de subjetividades sexo-disidentes), también funcionan como heridas que la poesía indaga para explorar su alcance ético, político y poético. Para profundizar en estudios sobre la vergüenza remito también al trabajo de Eve Kosofsky Sedgwick Touching Feeling: Affect, Pedagogy, Performativity, consignado en la bibliografía. 
sugestiva entonces la referencia a los vellos trenzados y los pelos que develan una entrada. ¿La entrada a qué? ¿A la escritura? ¿Al cuerpo de una mujer durante el acto sexual? Para apoyar esta lectura cabe señalar aquí una conexión insoslayable: Eroica, de Bellessi, comienza así: "Entrar /[...] al desorden /de una zona /antípoda /Carnal su centro /Carnal el sueño /que la alude" (Bellessi, 315) ${ }^{19}$.

Pero, como señalé, Rosenberg no es explícita al respecto. Su escritura abandona lo plano, la lógica bidimensional del significante/significado, para proponer un lenguaje de múltiples dimensiones donde es posible plegar, hallar huecos, relieves, arrugas, opacidades. El trabajo artesanal de exploración de las diversas aristas de las palabras desarticula otras dicotomías como decir/callar, develar/ ocultar, explicitar/velar que, cuando refieren a la homosexualidad, como sostiene Kosofsky Sedgwick en Epistemología del armario, estructuraron la producción de todos los saberes y subjetividades del siglo XX.

En sintonía con lo desarrollado por Sedgwick, considero que una figura que desarma la dicotomía decir/callar y sus desagregados es la del secreto, en la que la clave no está ni en lo dicho ni en lo no dicho, sino en la relación, la interacción siempre singular entre decir y velar: en "el nudo /donde lo dicho enmudece" (Rosenberg PJS 19). En la lengua de Rosenberg se arman esos nudos, donde lo que se dice enmudece y también en los que lo silenciado puede mostrarse sin romper su condición silenciosa: "este ahora /inaprensible /que la voz acalla" (PJS 17). Anuncia desde los relieves del lenguaje, desde sus huecos, desde sus múltiples dimensiones, que hay algo que está sucediendo y no se está diciendo. Me recuerda, en ese sentido, a las palabras de val flores para referirse a la "escritura cuir": "escritura bastarda en la que el silencio mismo es ruptura, resistencia a un sistema de signos, que piensa por sustracción, en las páginas en blanco, las lagunas, las fronteras, los espacios, los agujeros en el discurso" (55).

Laura Arnés señaló también que en el campo de la narrativa la figura del secreto se constituyó en una estrategia de representación, de visualización y de enunciación por parte de las voces lesbianas (27), reguladas por el "control acústico" como modus operandi del poder. Leer la obra de Rosenberg a partir de estos lineamientos críticos permite exponer la distribución diferencial de las palabras y los silencios entre los cuerpos: quién puede decir qué, qué se calla, quiénes callan y quiénes no, qué se dice, qué se asume, qué se codifica y decodifica, etc. Y la poeta insinúa este fenómeno: "Las palabras /tendrían que ser heridas /de cualquiera" (Rosenberg PJS 34), pero no lo son. No todos los cuerpos tienen la misma posibilidad de acceso a la (auto)representación. Y las subjetividades lesbianas tienen una amplia experiencia en ese sentido con el silenciamiento y con la invisibilización.

Como quien se dispone a orar en "un antro de fe" (MDM 76), Rosenberg se inclina ante la escritura y pide: "Manda, / palabra, /lo que anda /más oscuro entre la noche, /lo olvidado /tantas veces, lo no dicho /a decir" (PJS 17). Esta interpelación parece haber sido escuchada y tomada por Bellessi, quien cuatro años

19 El destacado es mío. 
después publica Eroica, libro en el que lo olvidado tantas veces, lo no dicho, se dice, se explicita, emerge sin eufemismos en la superficie textual del poemario.

\section{Despedida provisoria}

Las inflexiones lesbianas de la voz poética de Rosenberg están en los huecos, veladas entre los versos. Es la materialidad misma del lenguaje la que a la vez que las disimula las hace posibles, como un secreto que existe a condición de un decir que está replegado. Se murmura, se codifica, se esconde y aparece en las entrelíneas, en los silencios, en los espacios en blanco en donde acontece, como afirma Francine Masiello, algo del orden de lo aberrante, de lo inesperado. Al leer su poética desde una perspectiva que pone el acento en la dimensión de la sexualidad, aparecen las aberraciones, las irreverencias que con destreza la poeta trama entre sus versos y que horadan, usualmente inadvertidas, los pilares que estructuran las narrativas en torno a las subjetividades sexo-generizadas de la época.

Pasajes y Madam son lugares donde predomina la transgresión; espacios donde la poeta esparció las desobediencias de su voz como migas que aún hoy es necesario intuir, rastrear, oír, seguir.

\section{Referencias bibliográficas}

Ahmed, Sarah. La politica cultural de las emociones. 2004. México, UNAM, 2018.

Arnés, Laura. Ficciones lesbianas. Literatura y afectos en la cultura argentina. Buenos Aires, Madreselva, 2016.

Bellessi, Diana. Tener lo que se tiene. Córdoba, Adriana Hidalgo, 2009.

Butler, Judith. Deshacer el género. 2004. Barcelona, Paidós, 2006.

. El género en disputa. Barcelona, Paidós, 1990.

Cano, Virginia. Ética tortillera: ensayos en torno al ethos y la lengua de las amantes. Buenos Aires, Madreselva, 2015.

Dahbar, M. Victoria. Marcos temporales de la violencia. Hacia una configuración de lo humano-inhumano. Buenos Aires, Teseo, 2020.

Deleuze, Gilles. En medio de Spinoza. Buenos Aires, Cactus, 2003.

flores, val. Interruqciones. Ensayos de poética activista. Escritura, política, pedagogía. Neuquén, La mondonga dark, 2013.

Freeman, Elizabeth. Time binds. Queer Temporalities, Queer Histories. Durham, Duke University Press, 2010. 
Genovese, Alicia. La doble voz. Poetas argentinas contemporáneas. 1998. Córdoba, Eduvim, 2015.

Jiménez España, Paula. "Sin repetir y sin soplar". Página 12, Buenos Aires, 5 de julio de 2019.

Kosofsky Sedgwick, Eve. Epistemología del armario. 1990. Barcelona, De la tempestad ediciones, 1998.

. Touching Feeling: Affect, Pedagogy, Performativity. Durham, Duke University Press, 2003.

Love, Heather. Sintiéndose rezagad*. La pérdida y las politicas de la historia queer. S/f, http://hermosxsperdedorxs.tumblr.com/post/89136655072/sintiendose-rezagad-lap\%C3\%A9rdida-y-las-politicas

Mallol, Anahí. "Escritura y subjetividad. Poetas argentinas en los 80: entre la lírica y los géneros menores". Inti: Revista de literatura hispánica, $\mathrm{n}^{\circ} 52$, año 2000, p. 33-56.

Mallol, Anahí. "Lo que sólo las chicas saben. El amor entre mujeres en las poetas jóvenes de los 90". Lectures du genre, no 10, 2013, pp. 84-92.

Masiello, Francine. El cuerpo de la voz (poesía, ética y cultura), Rosario, Beatriz Viterbo Editora, 2013.

Meschonnic, Henri. La poética como crítica del sentido. Buenos Aires, Mármol izquierdo, 2007.

Molloy, Sylvia. "De Safo a Baffo. La diversión de lo sexual en Alejandra Pizarnik". Sexo y sexualidades en América Latina, compilado por Daniel Balderson y Donna J. Guy. Buenos Aires, Paidós, 1998, pp. 357-367.

. En breve cárcel. Buenos Aires, Fondo de Cultura Económica, 2011.

Rais, Hilda. "Lesbianismo. Apuntes para una discusión feminista”. Potencia Tortillera. http://potenciatortillera.blogspot.com/1984/11/hilda-rais.html

Rich, Adrienne. "Compulsory heterosexuality and lesbian existence". Signs: journal of women un culture and society, vol $5, \mathrm{n}^{\circ} 4$, University of Chicago, 1980, pp. 631-660.

Richard, Nelly. Feminismo, género y diferencia(s). Santiago de Chile, Palinodia, 2008.

Roffé, Reina. Monte de Venus. Buenos Aires, Corregidor, 1976.

Rosenberg, Mirta. El árbol de palabras. Buenos Aires, Bajo la luna, 2018.

Sáez, Javier. Teoría queer y psicoanálisis. Madrid, Síntesis, 2008.

Suarez Briones, Beatriz (ed.). Las lesbianas (no) somos mujeres. Barcelona, Icaria, 2013.

Wittig, Monique. El pensamiento heterosexual y otros ensayos. 1992. Madrid, Egales, 2006. 